\title{
Life Support with Failures and Variable Supply
}

\author{
Harry Jones ${ }^{*}$ \\ NASA Ames Research Center, Moffett Field, CA, 94035-0001
}

\begin{abstract}
The life support system for long duration missions will recycle oxygen and water to reduce the material resupply mass from Earth. The impact of life support failures was investigated by dynamic simulation of a lunar outpost habitat life support model. The model was modified to simulate resupply delays, power failures, recycling system failures, and storage failures. Many failures impact the lunar outpost water supply directly or indirectly, depending on the water balance and water storage. Failure effects on the water supply are reduced if Extra Vehicularactivity (EVA) water use is low and the water supply is ample. Additional oxygen can be supplied by scavenging unused propellant or by production from regolith, but the amounts obtained can vary significantly. The requirements for oxygen and water can also vary significantly, especially for EVA. Providing storage buffers can improve efficiency and reliability, and minimize the chance of supply failing to meet demand. Life support failures and supply variations can be survivable if effective solutions are provided by the system design.
\end{abstract}

\section{Nomenclature}

$\begin{array}{ll}\text { CM } & =\text { Crew Member } \\ \text { Dfix } & =\text { Fixed Demand } \\ \text { EVA } & =\text { Extravehicular Activity } \\ \text { ISRU } & =\text { In Situ Resource Utilization } \\ \text { S } & =\text { Supply } \\ \text { Savg } & =\text { Average Supply } \\ \text { Smax } & =\text { Maximum Supply }\end{array}$

\section{Introduction}

$\mathrm{T}$ HIS work continues investigations using a lunar outpost habitat life support model. (Jones, 2008-01-2184), "Lunar Base Life Support Mass Flow and Recycling," described the crew requirements and steady state mass flows. (Jones, 2008-01-2017), "The Dynamic Impact of EVA on Lunar Outpost Life Support," showed the large impact of EVA cooling water needs on water balance. (Jones, 2009-01-2493), "Planning Dynamic Simulation of Space Life Support," discussed some background considerations in developing dynamic systems models. (Jones, 2009-01-2482), "Lunar Base Life Support Failure Analysis and Simulation," described the behavior of the model with failures in the scarce water case, which occurs for high EVA cooling water needs.

This paper describes the failures in the ample water case and for the extreme case where no EVA cooling water is needed at all and all food is dehydrated. It was originally assumed that EVA cooling water use would be high, as for Apollo, and water would be scarce. It now appears that advanced spacesuit designs can greatly reduce or eliminate EVA cooling water use and that water could easily be ample (Jones, 2009-01-2418). The ample water case may be more likely than the scarce water case. The case where no EVA cooling water is needed and all food is dehydrated is probably an unrealistic boundary case.

The minimum crew oxygen and water needs without EVA can approximately be met by recycling, even if only dehydrated food is supplied. If fully hydrated food is used, there will be a water surplus and the minimum crew needs can be met very easily.

Depending on the EVA cooling water needs and assuming the provision of fully hydrated food, the lunar base will operate in either an ample water or a scarce water mode. If the EVA water requirement is less than about 3 $\mathrm{kg} / \mathrm{EVA}$, water will be ample and all water and oxygen needs can be met by recycling. If the EVA water

\footnotetext{
${ }^{*}$ Systems Engineer, Bioengineering Branch, Mail Stop N239-8, AIAA Senior Member.
} 
requirement is much higher as for Apollo, water will be scarce and additional water must be resupplied. If no water is required for EVA suit cooling, the water needs can almost be met by recycling even if dehydrated food is used.

The most basic external off-nominal event that can affect life support is a delay of the resupply mission. If the lunar base is in the ample water mode, with hydrated food and low EVA cooling water needs, only food is resupplied during normal operations. The crew will have adequate life support as long as the food lasts. If the lunar base is in a scarce water mode, food and water must be resupplied during normal operations. A cessation of EVA will stop EVA water use, and this places the lunar base in an ample water mode. In either case, the crew will have adequate life support as long as the food lasts.

Another fundamental off-nominal event that can affect life support is a total power outage, which would stop all life support processing. Limited power, if available, should be used to provide the most urgent life support function, carbon dioxide removal. The model was also used to investigate recycling processor and storage failures. Most of these failures have less impact than a resupply or total power failure, but again carbon dioxide removal is most urgent.

Additional water or oxygen can be supplied by scavenging unused lunar lander propellant or by production from lunar regolith, but the amount obtained can vary significantly. Water or oxygen will be used to support the crew in the base habitat and rovers and during EVA, and the amount demanded for EVA can vary significantly. The life support system must meet crew needs even though material supply and demand will be variable. Designing the system to provide storage buffers can increase resource use efficiency, improve supply reliability, and reduce the need for resupply.

\section{Assumed lunar mission and life support system}

The Constellation program envisioned a permanent lunar outpost with four-person crews rotated every six months and overlapping for one month. Automated resupply occurred three months into each mission. EVA was performed by alternating two-person teams, six days per week.

The outpost habitat model includes the crew, atmosphere, life support processors, and storage. The simulation model of the Lunar outpost habitat life support was developed in MATLAB/Simulink ${ }^{\mathrm{TM}}$. Its major components are the crew, the habitat atmosphere, the life support processors, and life support and waste storage. The life support model corresponds to a standard recycling life support system design, as implemented in the International Space Station. A full description is given in (Jones, 2009-01-2482).

We assume an ample water environment corresponding to an EVA cooling water requirement of $2 \mathrm{~kg} / \mathrm{EVA}$ Water will accumulate at $0.28 \mathrm{~kg} / \mathrm{CM}$-day. The clean water storage tank can be filled, providing a material buffer in case of failures. Additional or scavenged storage tanks can be filled as emergency reserves. It is assumed that carbon dioxide and waste water are recycled with 100 percent efficiency, and urine with 85 percent efficiency. Brine and feces water are not recovered.

With the EVA cooling water requirement at $2 \mathrm{~kg} / \mathrm{EVA}$, there is ample water. Recycling gives an excess of water that can be used to replace the used water and to continually increase the stored water. No water is resupplied from Earth. The maximum water storage is set at 60 days supply, $1,073 \mathrm{~kg}$. An initial amount of $600 \mathrm{~kg}$, about 34 days supply, is provided. At an average water surplus of about $0.28 \mathrm{~kg} / \mathrm{CM}$-day, it will require more than two missions of 180 days to increase the water storage from $600 \mathrm{~kg}$ to the maximum $1,073 \mathrm{~kg}$. 


\section{Simulation of lunar outpost life support on an initial mission}

The model was used to simulate the first 180 day mission with ample water corresponding to a low EVA cooling water requirement of $2 \mathrm{~kg} / \mathrm{CM}-\mathrm{EVA}$. The crew arrives on day 1 and is resupplied on day 90 . Figure 1 shows the behavior of the masses of the food, water, and oxygen for an initial mission with ample water.

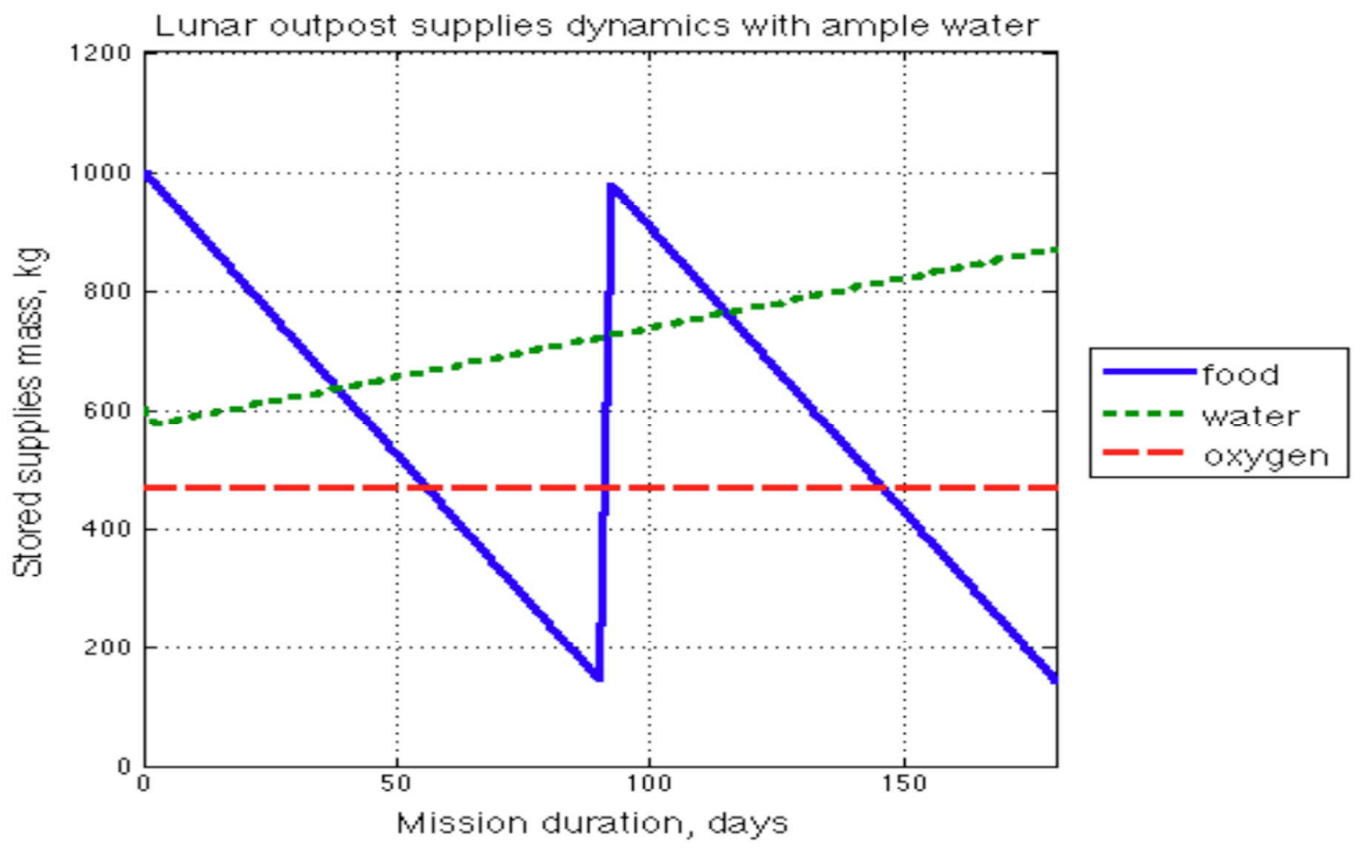

Figure 1. Masses of food, water, and oxygen on an initial 180 day mission with ample water.

The stored food is consumed at a steady rate and declines down to the 15 day reserve level $(\sim 140 \mathrm{~kg})$ at day 90 , when it is restored to the original amount by the automated consumables delivery. After a small initial drop due to wastewater buffer filling, the amount of stored clean water increases at a steady rate due to recycling. The water storage capacity is not reached. All consumed oxygen is replaced by recycling.

\section{Follow-on mission life support with ample water and a resupply failure}

The model was used to simulate a follow-on 180 day mission in a permanently occupied lunar base with ample water in which the anticipated 90 day resupply of food fails to occur. The water storage tank is filled to the maximum. There is no need to resupply water in this ample water case. To conserve the available food after the resupply failure, EVA is immediately stopped. Figure 2 shows the behavior of the masses of the food, water, and oxygen. 


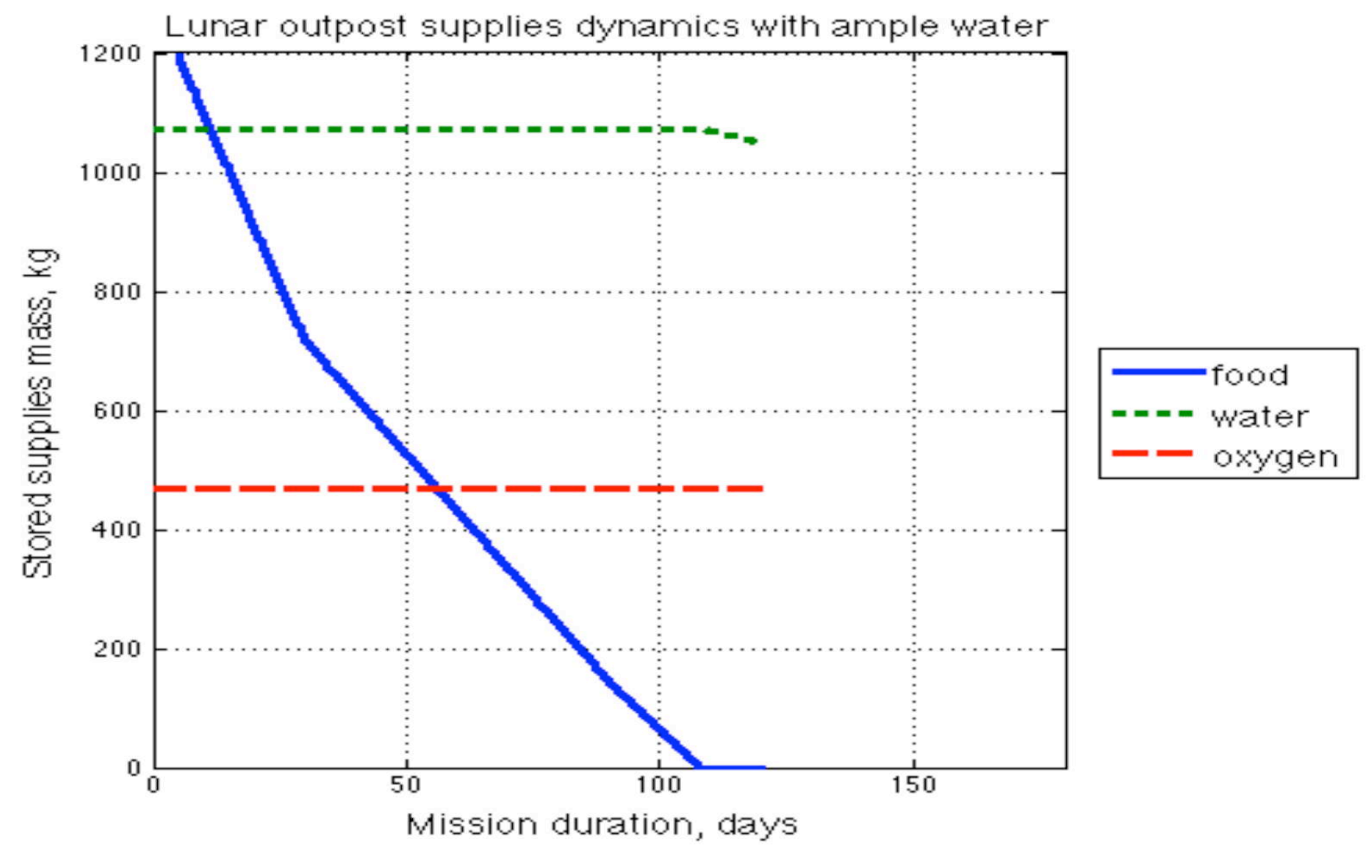

Figure 2. Masses of food, water, and oxygen on a follow-on mission with ample water and no resupply.

The behavior of food and oxygen stores is the same as for the scarce water case, since EVA is stopped. The water stored remains at its maximum as long as hydrated food is being consumed and the water is recovered. The 15 days reserve of food includes the added food provided to support the scheduled EVA, so the food lasts about 18 days at the use rate for no EVA. After the food runs out, the water storage begins to decline. The crew is without food if resupply fails. This is the essential problem, and it does not change whether water is scarce or ample. In this case of ample water (for hydrated food and low EVA cooling water needs), a large reserve of water could be built up if there were adequate storage capacity.

\section{Follow-on mission life support with ample water and a total power failure}

The model was used to simulate a follow-on 180 day mission with ample water in which a power failure stops the operation of all life support equipment on day 120. Figure 3 shows the expected decline of the lunar habitat stores of food, water, and oxygen.

The power failure on day 120 halts all the life support system processors. EVA is stopped that same day to conserve resources. It is assumed that the stored food, water, oxygen, and other materials can be accessed and used during the power failure. The most acute problem is the rapid build up of carbon dioxide in the habitat atmosphere. Stored nitrogen and oxygen are used to dilute the carbon dioxide in the habitat, but the added survival time is only about 5 to 7 days. Because of the total power failure, oxygen cannot be generated from the stored water.

Figure 4 shows the habitat atmosphere masses of nitrogen, oxygen, and carbon dioxide before and after the total power failure. used.

The habitat oxygen is vented to remove carbon dioxide and goes to zero shortly after all the stored oxygen is 


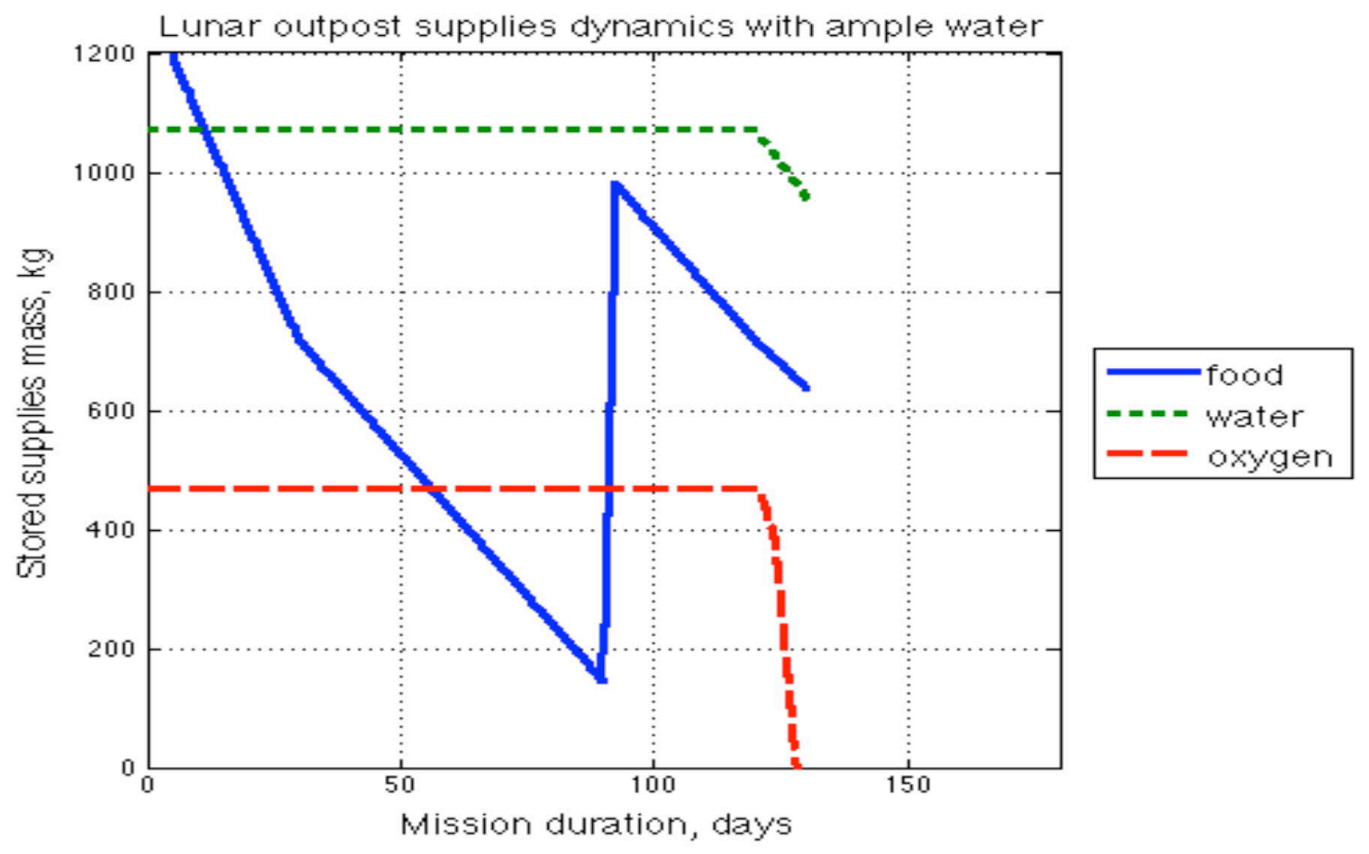

Figure 3. Masses of food, water, and oxygen on a follow-on mission with ample water and a total power failure.

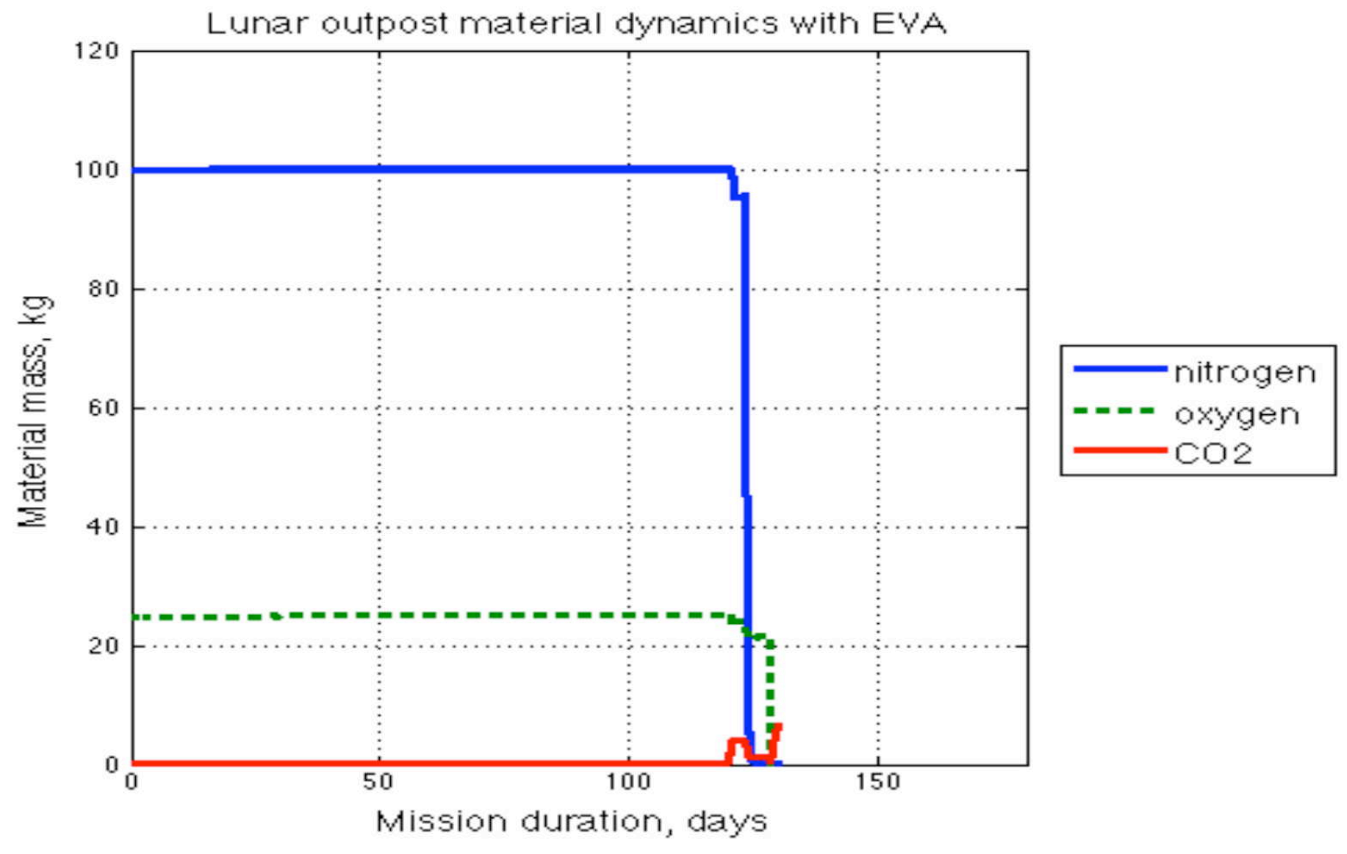

Figure 4. Masses of nitrogen, oxygen, and carbon dioxide in the habitat after a total power failure (on a follow-on mission with ample water).

\section{Follow-on mission life support with ample water and different processor failures}

The model was used to simulate follow-on 180 day missions with ample water in which different processors fail on day 120 . 


\section{A. Carbon dioxide removal failure}

The model was used to simulate a follow-on 180 day mission with ample water in which the carbon dioxide removal system fails on day 120 and EVA is halted. Figure 5 shows the lunar habitat stores of food, water, and oxygen.

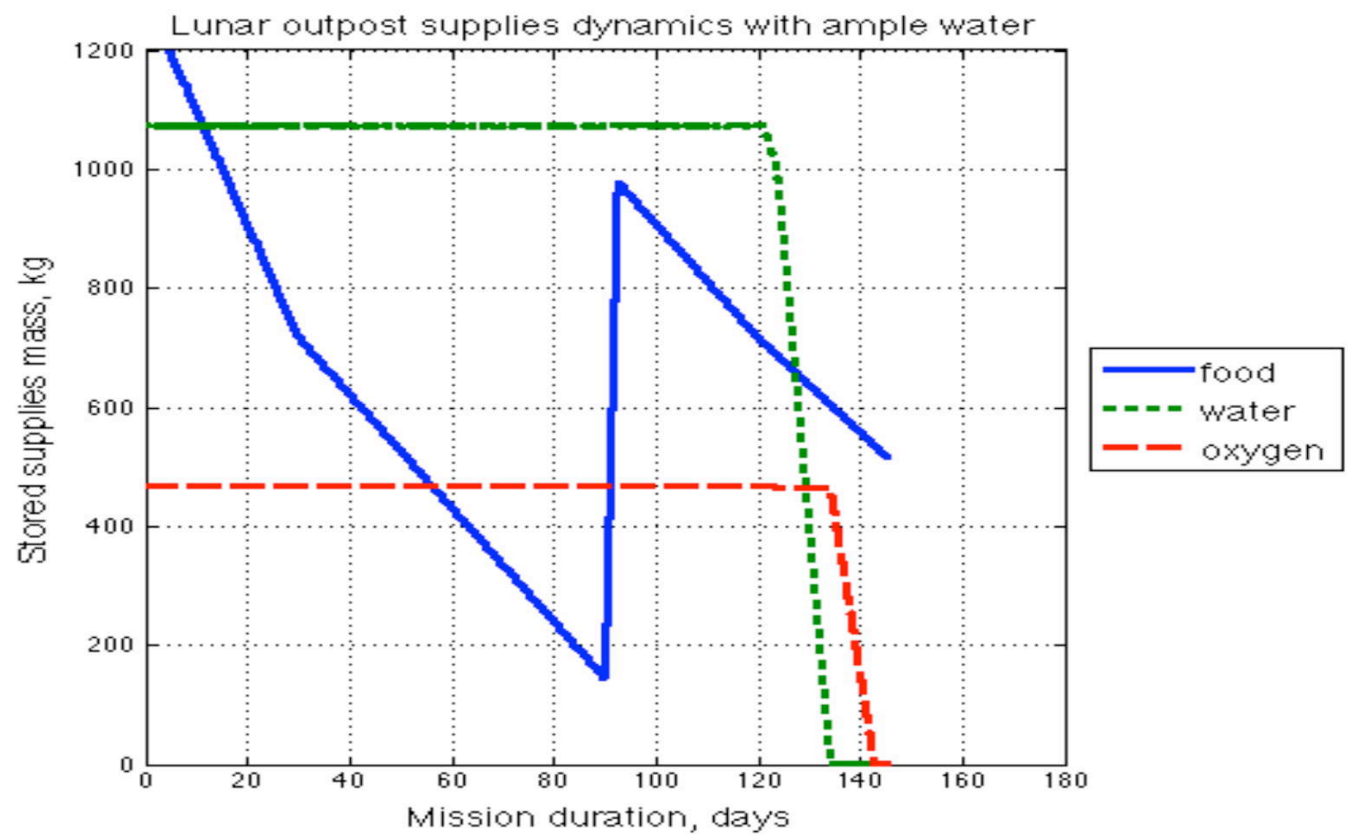

Figure 5. Masses of food, water, and oxygen on a follow-on mission with ample water and a carbon dioxide removal failure.

After the carbon dioxide removal system failure on day 120, nitrogen and oxygen and then only oxygen are used to dilute the carbon dioxide in the habitat. Water is converted to oxygen to maintain the oxygen store, and when the water is gone, the stored oxygen is depleted. The masses of nitrogen, oxygen, and carbon dioxide in the habitat are similar to those in the scarce water case. (Jones, 2009-01-2482) Because of the somewhat larger water stored in the ample water case, the crew survival time is a few days longer than in the scarce water case.

The crew can survive a carbon dioxide removal failure for a few weeks by diluting the habitat carbon dioxide with stored and generated oxygen. Suppose that the spacesuits are functional and can provide carbon dioxide removal. Crewmembers could survive for days outside in the spacesuits, but would have limited ability to eat or drink. Having two crew always outside in spacesuits and two in the habitat would effectively cut the crew carbon dioxide generation in the habitat in half, from four to two crew, and so double the survival time. Having three crew always outside would cut the crew carbon dioxide sources in the habitat from four to one and quadruple the survival time. Each crewmember would still have six hours inside per day.

\section{B. Humidity removal failure}

The model was used to simulate a follow-on 180 day mission with ample water in which humidity removal fails on day 120. The conversion of water to oxygen was not stopped to conserve water, so the amount of stored oxygen remains constant. EVA was stopped on day 160, reducing the rate of water store decline. Figure 6 shows the expected decline of the lunar habitat stores of food and water.

The water supply declines at about the same rate as the food, but food will be resupplied on day 180 and water will not, since it is not usually needed or resupplied in this ample water case. The decision to suspend EVA would depend on the prospects for humidity removal repair or water resupply. Although humidity condensate is not available, urine and hygiene wastewater are recycled. 


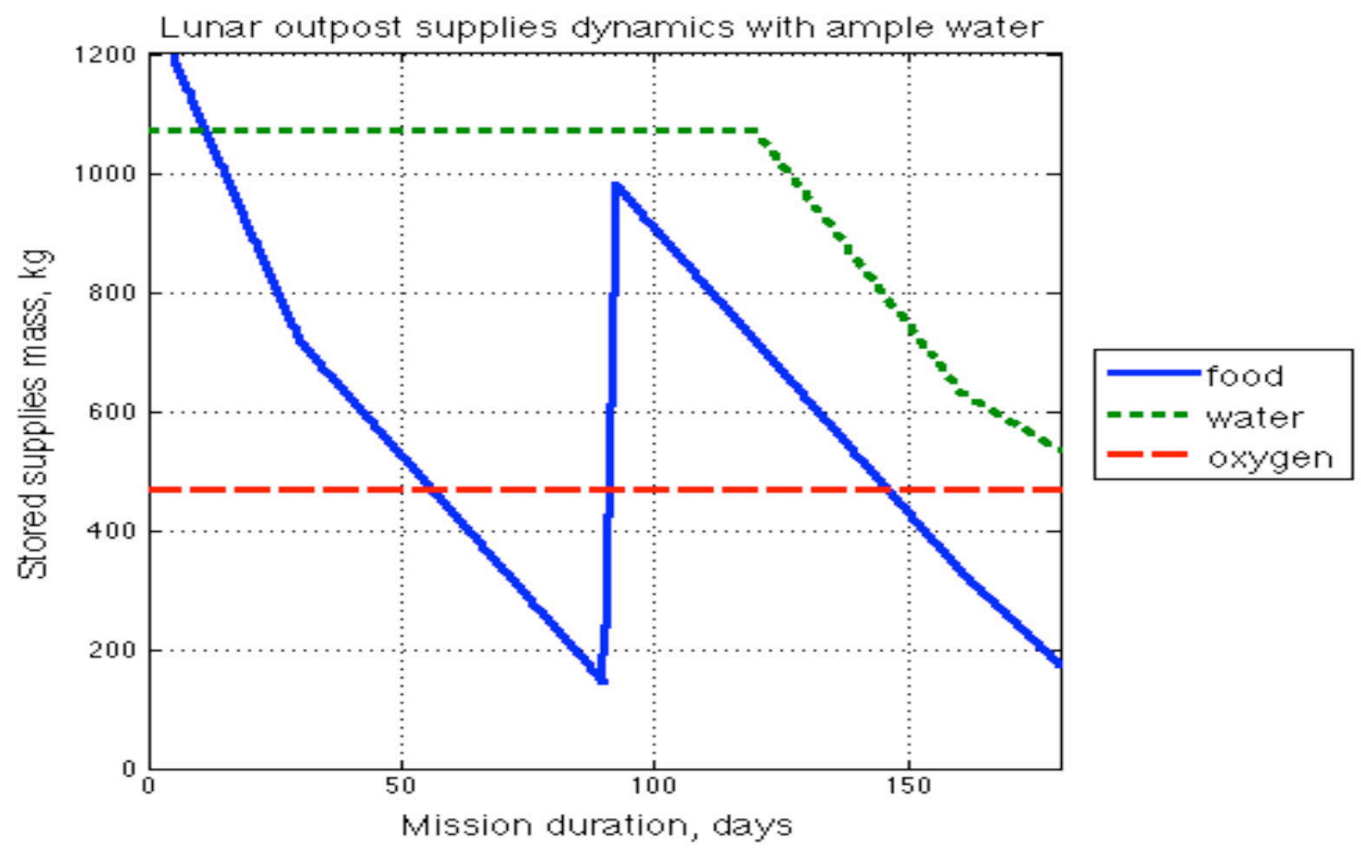

Figure 6. Masses of food, water, and oxygen on a follow-on mission with ample water and a humidity removal failure.

\section{Waste water purification failure}

All waste water is recycled by the waste water purification processor. The model was used to simulate a followon 180 day mission with ample water in which a waste water processor fails on day 120. Unlike the corresponding scarce water case, the conversion of water to oxygen was not stopped to conserve water. EVA was stopped on day 160 , reducing the rate of water store decline. Figure 7 shows the expected decline of the lunar habitat stores of food, water, and oxygen.

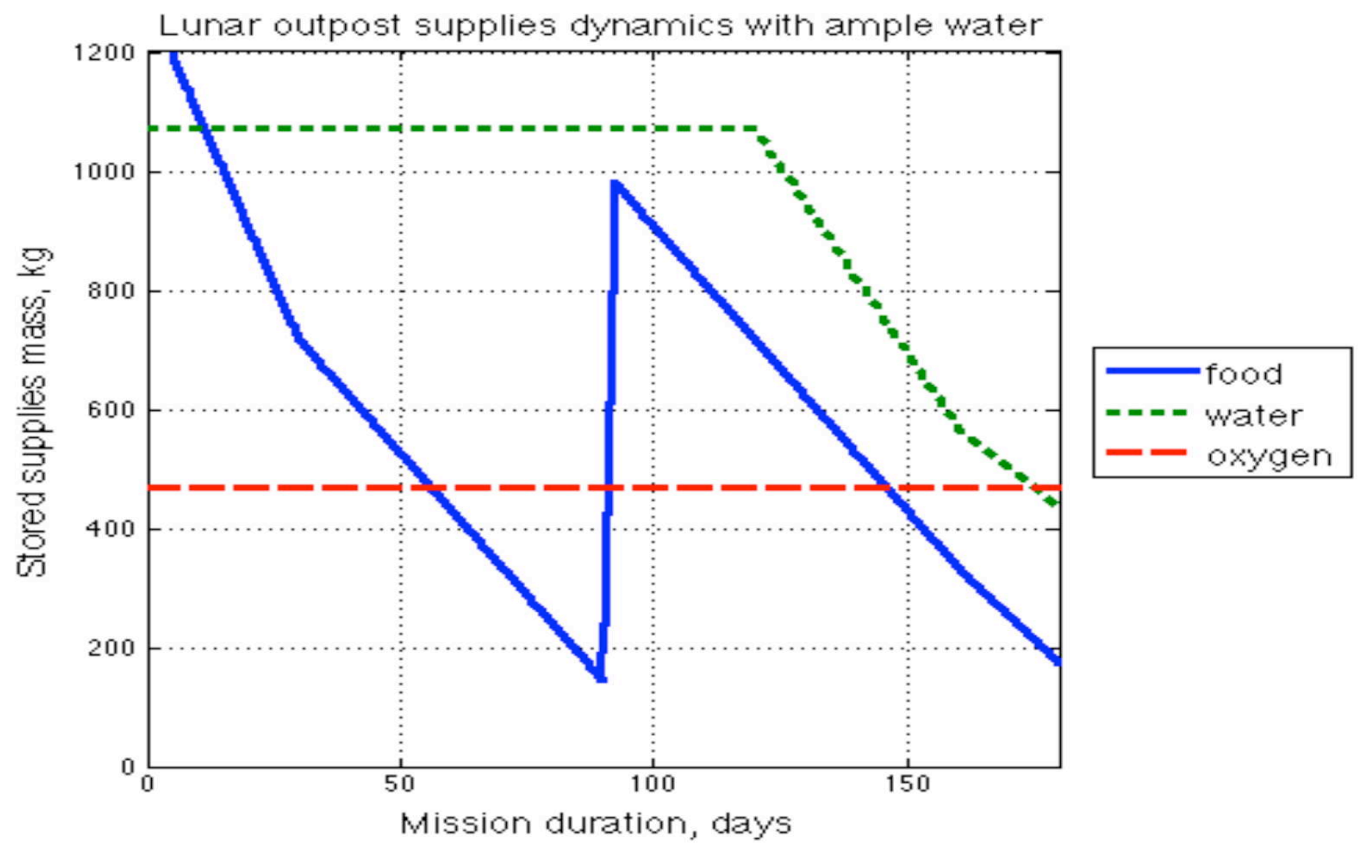

Figure 7. Masses of food, water, and oxygen on a follow-on mission with a waste water processor failure. 
The result is similar to a humidity removal failure, except that the water supply declines more rapidly. The wastewater processor failure removes about two-thirds more water per day from the recycled stream than a humidity removal failure. The only continuing source of clean water is carbon dioxide reduction. EVA can be suspended, depending on the prospects for repair or resupply.

\section{Other processor failures}

Urine purification provides about 25 percent and carbon dioxide reduction provides about 14 percent of the total recycled water, so their failures will have less impact than a waste water processor failure or even a humidity removal failure. If the oxygen generator fails, the very large emergency oxygen store provided initially provides oxygen sufficient for 105 days.

\section{Follow-on mission life support with ample water and different storage failures}

In the ample water case, as for the scarce water case, storage failures were considered for the habitat atmosphere (nitrogen and oxygen), the unrecyclable supplied materials (food, nitrogen, and hydrogen), the recyclable consumables (oxygen and water), the recyclable wastes (carbon dioxide, waste water, and urine), and the unrecyclable wastes (brine, methane, and feces). The behavior does not change significantly between the scarce and ample water cases, except for a clean water storage failure.

\section{A. Clean water storage failure}

The model was used to simulate a follow-on 180 day mission with ample water in which the clean water storage fails on day 120, so that all the water is lost. EVA and the conversion of water to oxygen continue uninterrupted. Figure 8 shows the loss of stored water and its gradual restoration after the loss.

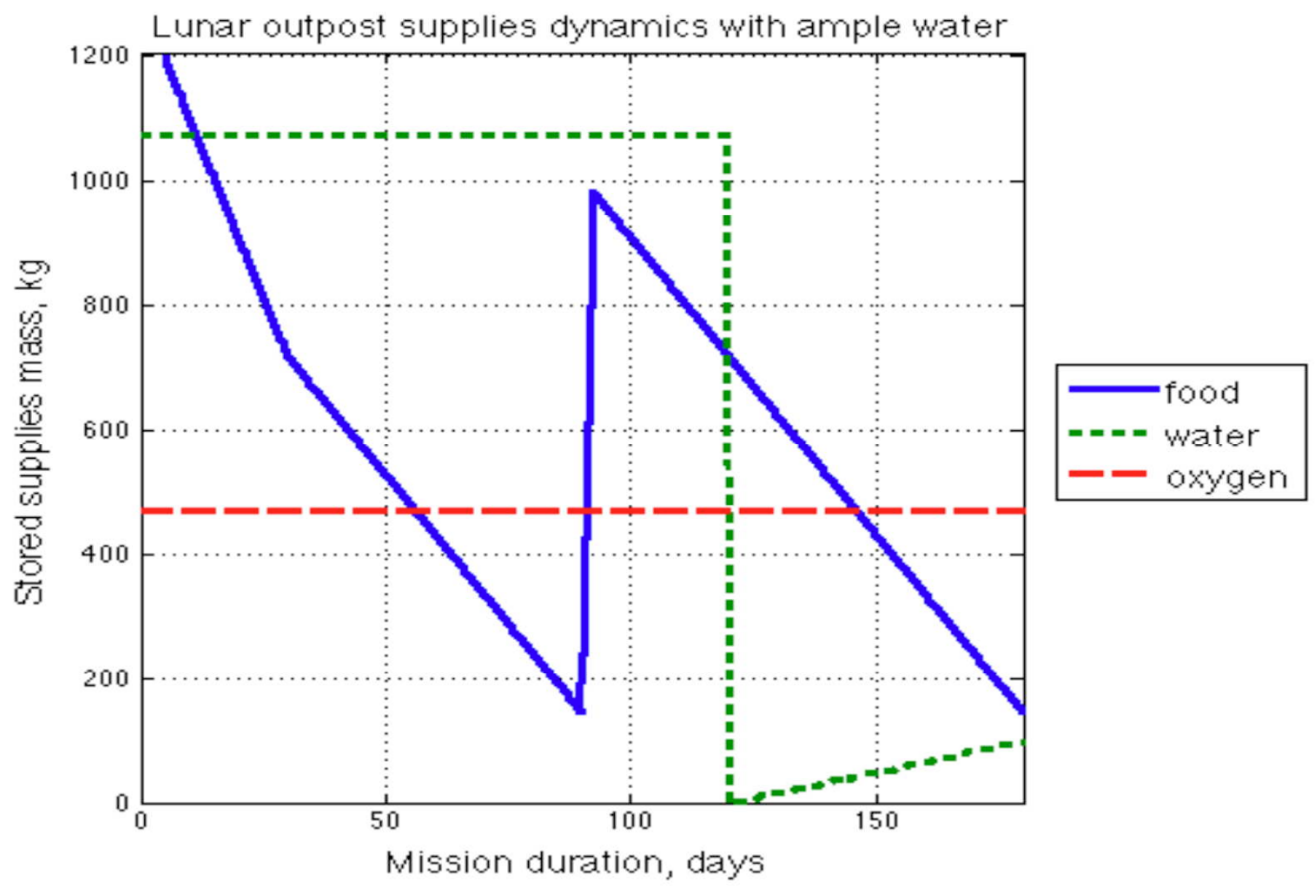

Figure 8. Masses of food, water, and oxygen on a follow-on mission with a clean water storage failure.

The stopping of EVA and of the conversion of water to oxygen would provide a much faster increase in stored water, but stored oxygen would decline. A water loss is not as critical in the case of ample water as for scarce water, since the stored water increases throughout the mission. See Fig. 1. In the case of scarce water, stored water loss is more critical, since the stored water declines throughout the mission and water supply limits the mission duration. (Jones, 2009-01-2482, Fig. 3) In general, a low EVA cooling water requirement leading to ample water provides increased robustness against water related failures. Survival time is increased and there is more ability to continue EVA. 


\section{Life support with no EVA cooling water and no water in food}

The model was modified to simulate the low resupply case where no EVA cooling water is needed and the food is completely dehydrated. This case is an unlikely lower bound for the lunar habitat, but corresponds to a Mars transit mission with no EVA. Previous analysis indicated that no water or oxygen resupply is needed, and all water and oxygen can be produced by recycling, if there are no EVA or recycling losses. However, carbon dioxide is lost during EVA and recycling will not be 100 percent efficient.

\section{A. Model modifications}

The initial mission water supply and the maximum storage capacity of water for the zero EVA cooling water case are the same as for the $2 \mathrm{~kg} / \mathrm{CM}-\mathrm{EVA}$ case, $600 \mathrm{~kg}$ and $1,073 \mathrm{~kg}$, respectively. The mid mission resupply of water, and the initial resupply for a follow on mission, depend on the water usage and are considered below. The changes in the required food supply rates and storage capacity for dehydrated food are shown in Table 1.

Table 1. Quantity changes for dehydrated food.

\begin{tabular}{|l|r|r|l|}
\hline & hydrated food & dehydrated food & units \\
\hline Non EVA day water in food & 1.29 & 0.00 & $\mathrm{~kg} / \mathrm{CM}$-day \\
\hline Non EVA day food prep water & 2.50 & 3.79 & $\mathrm{~kg} / \mathrm{CM}$-day \\
\hline EVA day water in food & 1.89 & 0.00 & $\mathrm{~kg} / \mathrm{CM}$-day \\
\hline EVA day food prep water & 4.18 & 6.07 & $\mathrm{~kg} / \mathrm{CM}-$ day \\
\hline Food initial supply, first mission & 1,001 & 352 & $\mathrm{~kg}$ \\
\hline Food resupply, follow-on mission & 1,144 & 402 & $\mathrm{~kg}$ \\
\hline Food midmission resupply & 858 & 302 & $\mathrm{~kg}$ \\
\hline
\end{tabular}

The food supply at the beginning of a follow-on mission was $1,287 \mathrm{~kg}$ and now is $453 \mathrm{~kg}$, including the carried over reserve.

\section{B. Mass balance computation}

The average mass balance for the case where no EVA cooling water is needed and the food is completely dehydrated is calculated. Table 2 shows the recyclable outputs, recycled products, and needs on an average day, for no EVA cooling water and completely dehydrated food. The EVA schedule is as before, with two crew performing EVA six days per week.

Table 2. Crewmember life support recyclable outputs, recycled products, and needs on an average day for zero EVA cooling water and dehydrated food.

\begin{tabular}{|l|r|l|l|l|r|}
\hline Recyclable outputs & $\begin{array}{l}\mathrm{kg} / \mathrm{CM}- \\
\text { day }\end{array}$ & Recycled products & $\begin{array}{l}\mathrm{kg} / \mathrm{CM}- \\
\text { day }\end{array}$ & Needed products & $\begin{array}{l}\mathrm{kg} / \mathrm{CM}- \\
\text { day }\end{array}$ \\
\hline $\begin{array}{l}\text { Water equivalent of } \\
\text { carbon dioxide }\end{array}$ & 0.81 & $\begin{array}{l}\text { Water equivalent } \\
\text { of oxygen }\end{array}$ & 0.81 & $\begin{array}{l}\text { Water equivalent of } \\
\text { oxygen }\end{array}$ & 1.25 \\
\hline $\begin{array}{l}\text { Respiration and } \\
\text { perspiration water }\end{array}$ & 3.07 & Water & 3.07 & $\begin{array}{l}\text { Food preparation } \\
\text { and drinking water }\end{array}$ & 4.77 \\
\hline Urine & 2.03 & Water & 1.72 & Hygiene water & 0.40 \\
\hline Hygiene waste water & 0.38 & Water & 0.38 & & \\
\hline Hygiene latent water & 0.02 & Water & 0.02 & & 6.42 \\
\hline Totals & 6.31 & & 6.01 & & \\
\hline
\end{tabular}

The mass of the waste carbon dioxide and the product oxygen is given as water equivalent. This is the amount of water either produced using the recycled carbon dioxide or required to produce the generated oxygen. The outputs

Table 3. Water balance gains and losses.

\begin{tabular}{|l|r|r|}
\hline & \multicolumn{1}{l|}{$\begin{array}{l}\text { mass, } \\
\text { kg/CM-day }\end{array}$} & $\begin{array}{l}\text { water mass } \\
\text { equivalent, } \\
\text { kg/CM-day }\end{array}$ \\
\hline Metabolic water gain & 0.45 & 0.45 \\
\hline Respiration quotient loss & $1.11 \mathrm{O} 2$, & 0.15 \\
\hline EVA carbon dioxide loss & $1.34 \mathrm{CO} 2$ & 0.29 \\
\hline Urine brine loss & 0.35 & 0.30 \\
\hline Feces waler loss & 0.12 & 0.12 \\
\hline Net & & -0.41 \\
\hline
\end{tabular}
and products are those for an average day, considering EVA and non EVA days.

In a significant difference from the case of hydrated food, the needed products exceed the recycled products. All the required water and oxygen cannot be produced by recycling. The fundamental cause of this difference is the absence of water in the dehydrated food and the corresponding increase in the need for food preparation water. The water balance gains and losses are shown in Table 3. 
In the absence of EVA cooling water use and a hydrated food water supply, small water gains and losses are more significant. The net water loss in Table $3,0.41 \mathrm{~kg} / \mathrm{CM}$-day, is equal to the difference between the needed products and the available recycled products in Table 2. The sum of the EVA carbon dioxide, urine brine, and feces water losses is $0.71 \mathrm{~kg} / \mathrm{CM}$-day. Recovering 58 percent of these losses would provide all the needed water. The allowed margin for recycling loss is equal to the net metabolic water equivalent gain, $0.45-0.15=0.30 \mathrm{~kg} / \mathrm{CM}$-day.

Urine flush water is not considered in this report or implemented in the simulations. The nominal value for urine flush is $0.5 \mathrm{~kg} / \mathrm{CM}$-day. If this flush water was recovered at the urine processor efficiency of $0.85,0.075 \mathrm{~kg} / \mathrm{CM}$-day would be lost. However the limit on recovery is determined by the brine concentration, so perhaps more of the urine flush water could be recovered. In any case, the amount is relatively small.

The water gains and losses are all small numbers, based on the differences of averages of the larger and highly variable amounts of oxygen, water, and food used to support the crew. A workable system needs relatively large buffers and large reserves of materials, as assumed previously. The initial mission water supply is $600 \mathrm{~kg}$, and the maximum storage capacity of water is $1,073 \mathrm{~kg}$. The midmission resupply of water is equal to the 90 day loss for 4 crew, $0.41 * 4 * 90=148 \mathrm{~kg}$. The initial resupply for a follow on mission is equal to the 90 day usage plus 30 day usage for a second overlapping crew. $0.41 * 4 *(90+30)=197 \mathrm{~kg}$. This initial resupply restores the initial water storage level of $600 \mathrm{~kg}$. The resupplied water could be supplied in hydrated food, and would correspond to about one-third hydrated food and two-thirds dehydrated.

\section{Follow-on mission with no EVA cooling water and no water in food}

The model was modified to simulate the low resupply case where no EVA cooling water is needed, all food is dehydrated, and the loss of $0.41 \mathrm{~kg} / \mathrm{CM}$-day of water must be resupplied. The operation of the life support system with no EVA cooling water and dehydrated food was simulated, and the results are shown in Fig. 9. Water and food are resupplied on day 90 and follow a saw tooth pattern in time.

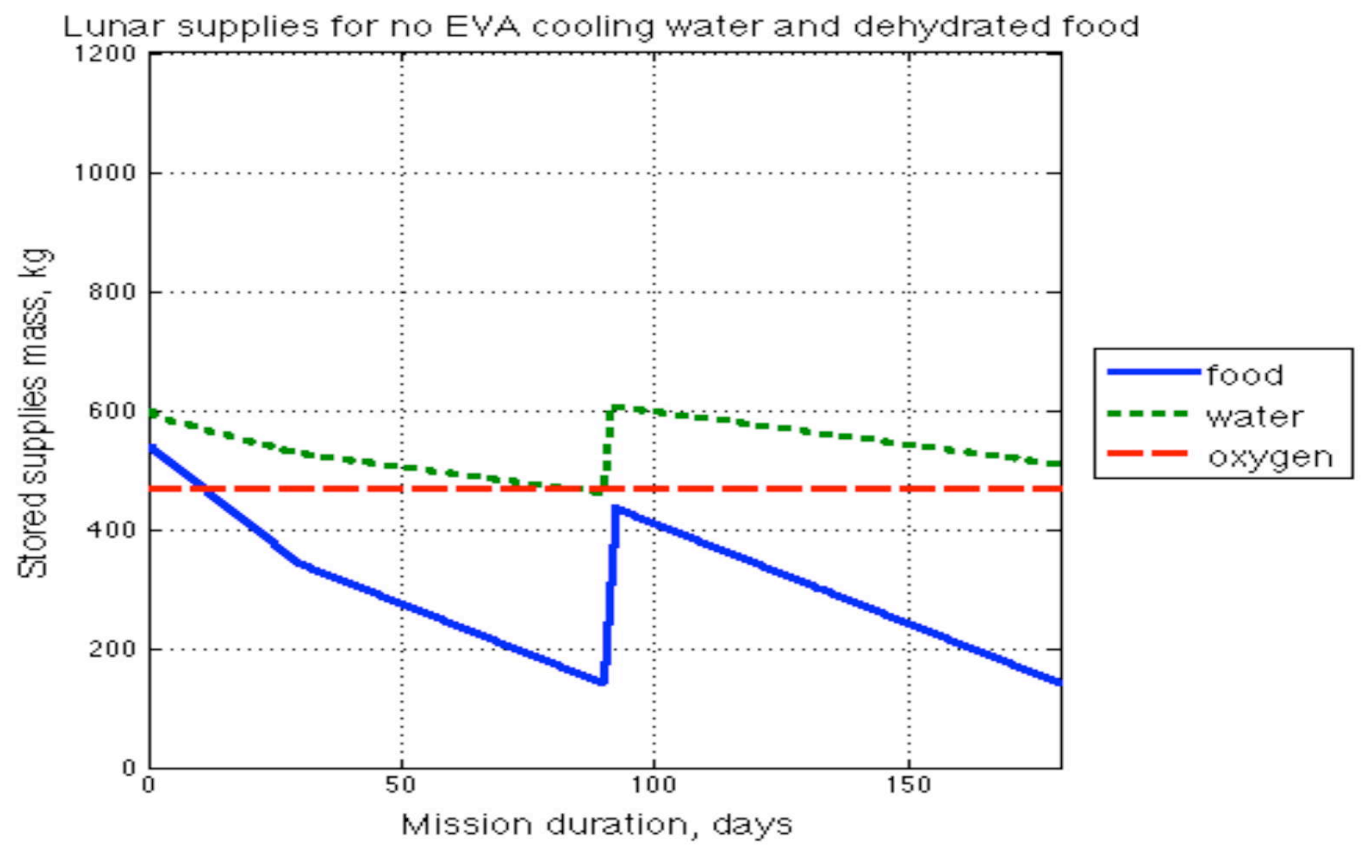

Figure 9. Masses of food, water, and oxygen on a follow-on mission with no EVA cooling water and dehydrated food. 


\section{Failures on a follow-on mission with no EVA cooling water and no water in food}

The model for the case where no EVA cooling water is needed and all food is dehydrated was used to simulate resupply failure, waste water processor failure, and clean water storage failure.

\section{Resupply failure}

The model was used to simulate a follow-on 180 day mission with no EVA cooling water and dehydrated food in which the anticipated 90 day resupply of food and water fails to occur. Figure 10 shows the behavior of the food, water, and oxygen storage.

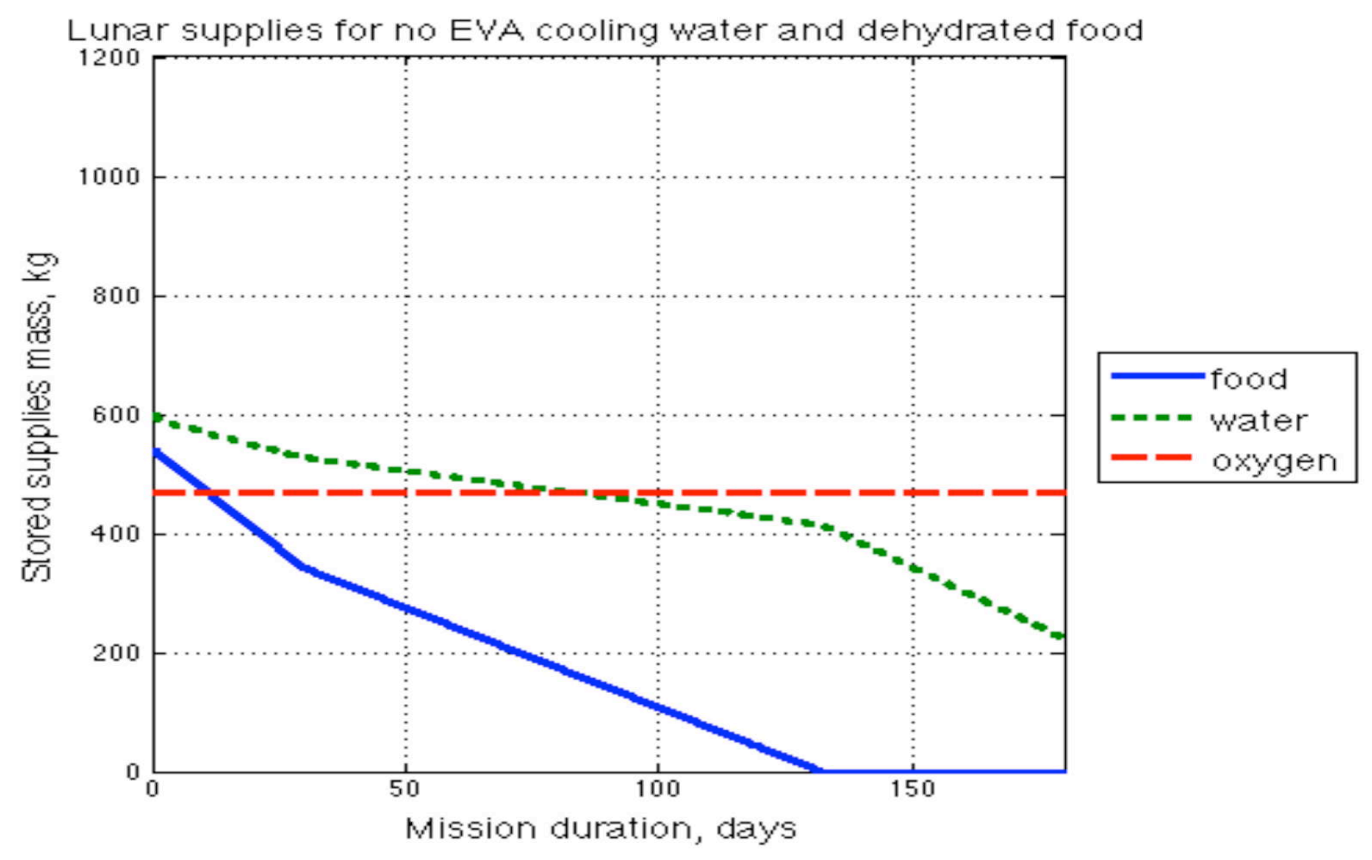

Figure 10. Masses of food, water, and oxygen on a follow-on mission with no EVA cooling water and dehydrated food and no resupply.

EVA is continued, even though suspending EVA would extend the food supply slightly. All the food is consumed by about day 130 . The stored water begins to decrease more rapidly then, since no more water is produced by the metabolism of food.

\section{Water purification failure}

The model was used to simulate a follow-on 180 day mission with no EVA cooling water and dehydrated food in which the waste water processor fails on day 120. EVA was stopped on day 130, slightly decreasing the rate of water storage decline. Figure 11 shows the behavior of the lunar habitat stores of food, water, and oxygen.

The stored water runs out on about day 165 , and oxygen storage begins to decline then, since no more water is converted to oxygen.

\section{E. Water storage failure}

The model was used to simulate a follow-on 180 day mission with no EVA cooling water and dehydrated food in which the clean water storage fails on day 120 , so that all the stored water is lost. EVA and the conversion of water to oxygen are also stopped on day 120 , because of the critical shortage of operational water. (EVA and the conversion of water to oxygen were not stopped in the case of a clean water storage failure with ample water, shown in Fig. 8.) Figure 12 shows the loss of stored water and its gradual increase after the loss.

The flow of recycled water is sufficient to meet current needs and the water storage increases. The oxygen store declines because water is not being converted to oxygen. Water and oxygen stores can to some extent substitute for each other. 


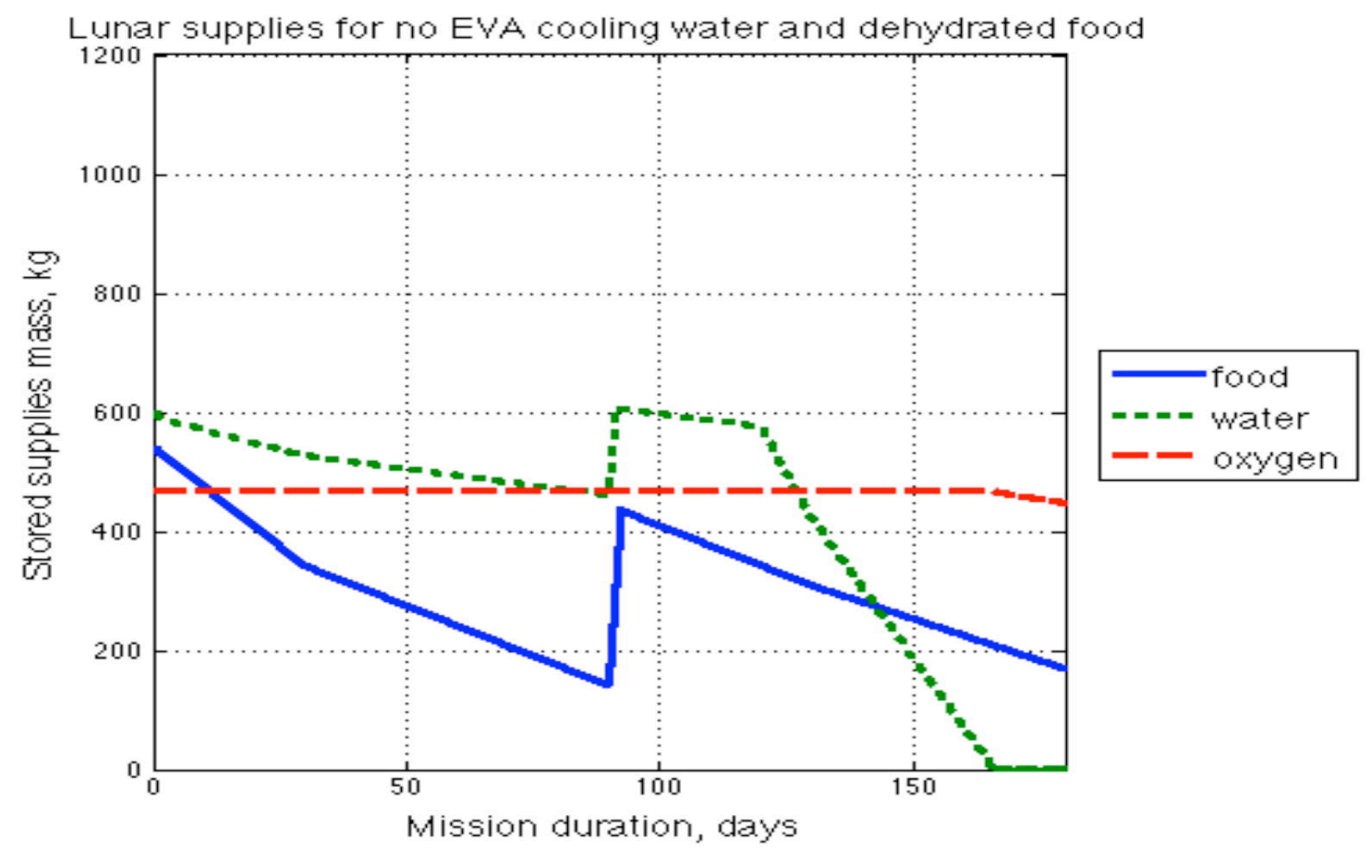

Figure 11. Masses of food, water, and oxygen on a follow-on mission with no EVA cooling water and dehydrated food and a wastewater purification failure.

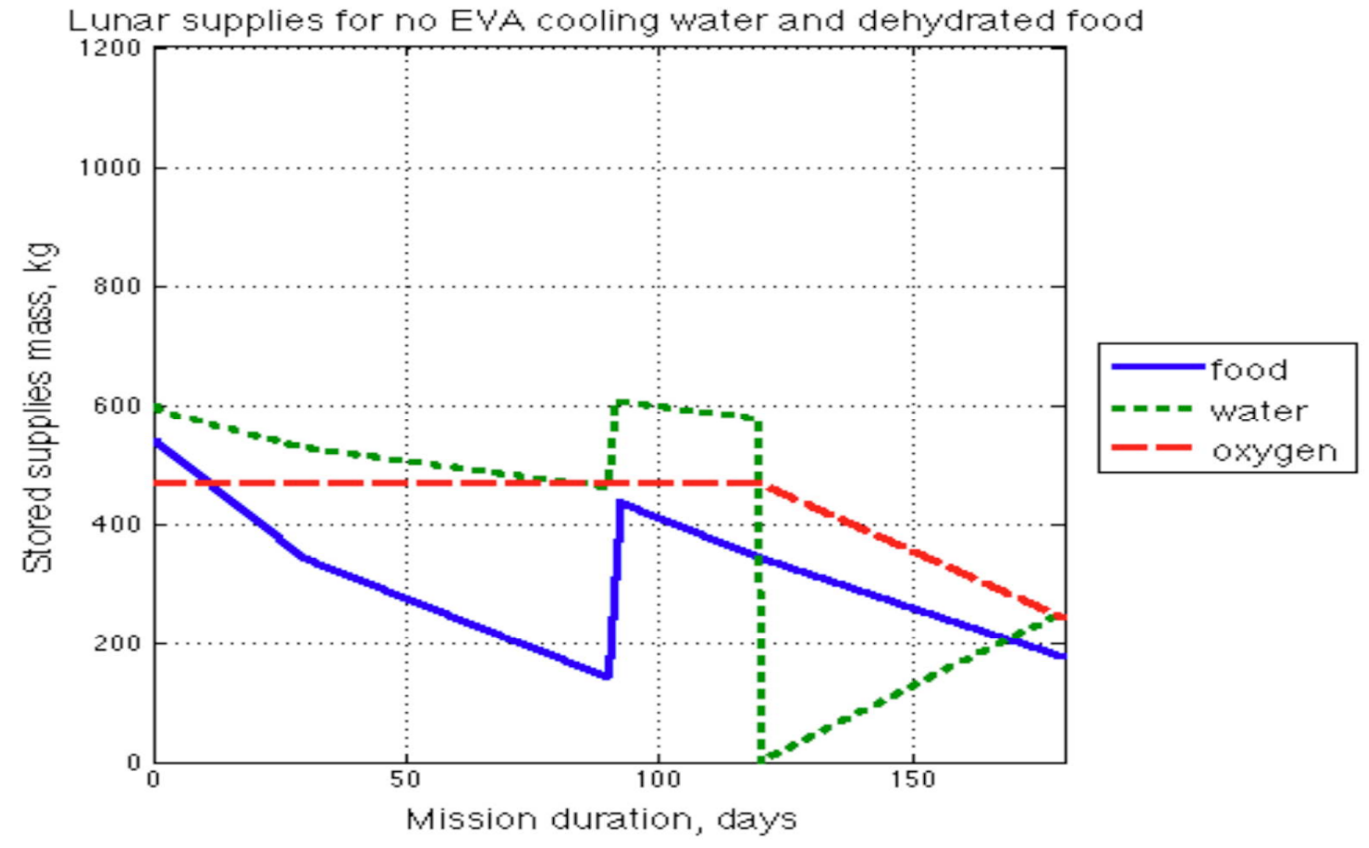

Figure 12. Masses of food, water, and oxygen on a follow-on mission with no EVA cooling water and dehydrated food and a clean water storage failure. 


\section{Failure scenario overview}

Table 4 provides an overview of the failure mode simulations.

Table 4. Overview of the failure mode figures 1 through 12.

\begin{tabular}{|c|c|c|c|c|}
\hline Figure & Figure title & Failure & Critical resource & $\begin{array}{l}\text { Available } \\
\text { time, days }\end{array}$ \\
\hline 1 & $\begin{array}{l}\text { Masses of food, water, and oxygen on an } \\
\text { initial } 180 \text { day mission with ample watcr. }\end{array}$ & None & & \\
\hline 2 & $\begin{array}{l}\text { Masses of food, water, and oxygen on a } \\
\text { follow-on mission with ample water and no } \\
\text { resupply. }\end{array}$ & Resupply & Food & 18 \\
\hline 3 & $\begin{array}{l}\text { Masses of food, water, and oxygen on a } \\
\text { follow-on mission with ample water and a total } \\
\text { power failure. }\end{array}$ & Power & $\begin{array}{l}\text { Carbon dioxide } \\
\text { free atmosphere }\end{array}$ & 7 \\
\hline 4 & $\begin{array}{l}\text { Masses of nitrogen, oxygen, and carbon } \\
\text { dioxide in the habitat after a total power failure } \\
\text { (on a follow-on mission with ample water). }\end{array}$ & $\begin{array}{l}\text { Same case as } \\
\text { Figure } 3\end{array}$ & & \\
\hline 5 & $\begin{array}{l}\text { Masses of food, water, and oxygen on a } \\
\text { follow-on mission with ample water and a } \\
\text { carbon dioxide removal failure. }\end{array}$ & $\begin{array}{l}\text { Carbon } \\
\text { dioxide } \\
\text { removal }\end{array}$ & $\begin{array}{l}\text { Carbon dioxide } \\
\text { free atmosphere }\end{array}$ & 30 \\
\hline 6 & $\begin{array}{l}\text { Masses of food, water, and oxygen on a } \\
\text { follow-on mission with ample water and a } \\
\text { humidity removal failure. }\end{array}$ & $\begin{array}{l}\text { Humidity } \\
\text { removal }\end{array}$ & Water & $\sim 300$ \\
\hline 7 & $\begin{array}{l}\text { Masses of food, water, and oxygen on a } \\
\text { follow-on mission with a waste water } \\
\text { processor failure. }\end{array}$ & $\begin{array}{l}\text { Waste water } \\
\text { processor }\end{array}$ & Water & $\sim 150$ \\
\hline 8 & $\begin{array}{l}\text { Masses of food, water, and oxygen on a } \\
\text { follow-on mission with a clean water storage } \\
\text { failure. }\end{array}$ & $\begin{array}{l}\text { Water } \\
\text { storage }\end{array}$ & Water & No limit \\
\hline 9 & $\begin{array}{l}\text { Masses of food, water, and oxygen on a } \\
\text { follow-on mission with no EVA cooling water } \\
\text { and dehydrated food. }\end{array}$ & None & & \\
\hline 10 & $\begin{array}{l}\text { Masses of food, water, and oxygen on a } \\
\text { follow-on mission with no EVA cooling water } \\
\text { and dehydrated food and no resupply. }\end{array}$ & Resupply & Food & 40 \\
\hline 11 & $\begin{array}{l}\text { Masses of food, water, and oxygen on a } \\
\text { follow-on mission with no EVA cooling water } \\
\text { and dehydrated food and a wastewater } \\
\text { purification failure. }\end{array}$ & $\begin{array}{l}\text { Waste water } \\
\text { processor }\end{array}$ & Water & 45 \\
\hline 12 & $\begin{array}{l}\text { Masses of food, water, and oxygen on a } \\
\text { follow-on mission with no EVA cooling water } \\
\text { and dehydrated food and a clean water storage } \\
\text { failure. }\end{array}$ & $\begin{array}{l}\text { Water } \\
\text { storage }\end{array}$ & Water & No limit \\
\hline
\end{tabular}

Figures 1 through 8 describe missions with ample water due to a low EVA cooling water requirement and the provision of hydrated food. Figures 9 through 12 describe missions where no EVA cooling water is needed and the food is completely dehydrated. In the latter case, less water is available and a water processor failure causes an earlier lack of water. 


\section{Using scavenged and in situ materials}

Additional oxygen and hydrogen can be supplied by scavenging unused lunar lander propellant. Oxygen can be produced from lunar regolith using ISRU (In Situ Resource Utilization) techniques. However, the supplied amounts will vary. The supply must meet crew demands or additional water or oxygen must be sent from Earth to make up the deficiency.

If the supply and demand were known exactly for each 180 day mision, the excess or deficiency could be calculated and the appropriate initial storage amounts provided. Variable supply and demand can be described by probability distributions, and the probability distribution of their difference determined by simulation. The likelihood of requiring additional supplies from Earth can be determined, along with its expected amount and variance.

If a series of 180 day missions begin at the same location, such as a 10 year lunar base, storing excess materials from one mission to the next can reduce the chance of failing to meet future demand and requiring additional supplies from Earth. Designing the system to provide a storage buffer will increase resource use efficiency and improvie supply reliability.

\section{A. Previous work}

Lange and Anderson investigated a lunar surface exploration scenario that includes lunar lander propellant scavenging, either using residual oxygen or converting the oxygen and hydrogen to water. They observe that the quantity of residual lander propellants available for scavenging is variable, as are the demands for oxygen and water for rover excursions, EVA, and other needs. They assume probability distributions for the variables and use Monte Carlo simulations to estimate the surpluses or deficits of water and oxygen on each 180-day mission over the 10year lunar base duration. The probability of having sufficient water or oxygen is used as the measure of system robustness.

High use of water for EVA suit cooling can result in a need for continuing water resupply. Lange and Anderson find that propellant scavenging and ISRU reduce the probability of needing resupply and can eliminate the need for resupply in some cases. They also note that the ability to recover water from brine and feces, while not always needed, does increase the system robustness, further reducing the probability of needing resupply. (Lange and Anderson)

\section{B. Potential amounts of scavenged and in situ materials}

Lander propellant scavenging can provide up to $400 \mathrm{~kg}$ of water per mission by combining the remaining hydrogen and oxygen in the lander fuel cells. (Linne et al.) (Lange) Hydrogen reduction of lunar regolith followed by water electrolysis could produce up to $1,000 \mathrm{~kg}$ of oxygen during a 180 day mission. (Lange)

\section{Impact on life support design for ample water}

Suppose that each crewmember goes on EVA three days per week, that the food is hydrated, and that each EVA requires $2 \mathrm{~kg}$ of suit cooling water, which is the ample water case. A crewmember's average consumption of oxygen is $1.11 \mathrm{~kg}$ per day and of water is $3.45 \mathrm{~kg}$ per day, not counting the water in the food. (Jones, 2009-01-2482) For four crew on an 180 day mission, oxygen consumption is $800 \mathrm{~kg}$ and water use is $2,480 \mathrm{~kg}$.

ISRU oxygen could meet crew needs, but the water from scavenged propellant is much less than the water requirement. Water recycling will be necessary, and will produce an average daily surplus of $0.5 \mathrm{~kg} / \mathrm{CM}$. (Jones, 2009-01-2482) ISRU and scavenging propellant are not necessary for life support in the ample water case, but could be used to build up stored stocks or for providing radiation shielding.

\section{Impact on life support design for scarce water}

If the EVA cooling water requirement is 5 rather than $2 \mathrm{~kg} / \mathrm{EVA}$, the average day surplus of $0.5 \mathrm{~kg} / \mathrm{CM}$ becomes an expected loss of $1 \mathrm{~kg} / \mathrm{CM}$-day. (Jones, 2009-01-2482) For four crew on an 180 day mission, the shortfall is 720 $\mathrm{kg}$ of water. This water must be supplied from Earth in addition to the water in hydrated food.

The water from scavenged propellant and produced using ISRU oxygen could meet this need. $440 \mathrm{~kg}$ of water can be produced by combining residual hydrogen and oxygen, and another $700 \mathrm{~kg}$ by combining residual propellant hydrogen with ISRU oxygen. (It may be difficult preserve all of the residual hydrogen until it can be processed into water.) (Linne et al.) Supplying water from Earth is very costly, and substituting less expensive scavenged or ISRU material is very attractive. 


\section{Scavenged and in situ supply variations}

The scavenged propellant can vary significantly. Notardonato estimates that the minimum total recoverable mass of oxygen is $132 \mathrm{~kg}$ and the maximum is $800 \mathrm{~kg}$, and that the minimum total recoverable mass of hydrogen is 141 $\mathrm{kg}$ and the maximum is $252 \mathrm{~kg}$. (Notardonato) Scavenged hydrogen is combined with ISRU oxygen to produce water. The amount of water provided by scavenging and ISRU may be more or less than needed.

Buffering is the solution to dynamic flow variations. The likelihood of a lack of water and a need to provide it from Earth can be reduced by providing a water storage buffer. If the average supply exceeds the average demand, the amount of stored water will increase. If a significantly large initial store of water is provided, the likelihood of a shortfall is further reduced.

\section{A. The effect of material supply variations}

The analysis starts with an extremely simple example. Suppose that during a space mission there is a fixed demand for some life support material, perhaps water. The fixed amount demanded is Dfix. Suppose that of this material has a free variable local supply, $\mathrm{S}$, where the amount $\mathrm{S}$ is greater than zero and less than Smax. Suppose that Smax > Dfix, so that sometimes the supply S exceeds the demand Dfix. In this case, the demand is met with no cost. However, sometimes $\mathrm{S}<\mathrm{Dfix}$ and there is a material shortfall equal to Dfix $-\mathrm{S}$. This shortfall amount must be supplied from Earth at a mass cost equal to Dfix $-\mathrm{S}$.

Using the free local supply S definitely saves mass and cost, but the amount saved depends on the probability distribution of $\mathrm{S}$ and its relation to Dfix. If the average $\mathrm{S}$, Savg is much less than the fixed demand, Savg $<<$ Dfix, we save Savg per emission, on average. If Savg is much greater than Dfix, Savg $>>$ Dfix, we typically save Dfix per mission. These are extreme cases. The above lunar base mission calculations show that the maximum supplied water is similar in magnitude to the demand. If Savg $\sim$ Dfix, the material supply will sometimes be excessive and sometimes deficient. This can be analyzed with the help of dynamic simulation.

\section{B. Dynamic simulation of material supply variations}

Suppose that the fixed amount demanded, Dfix, is $10 \mathrm{~kg}$. Suppose that the variable local supply, S, is uniformly distributed between 0 and $\operatorname{Smax}=20 \mathrm{~kg}$. A dynamic simulation is used to investigate the system behavior. The demand, an example random variable supply, and the resulting needed additional resupply for a sequence of twenty missions is shown in Fig. 13.

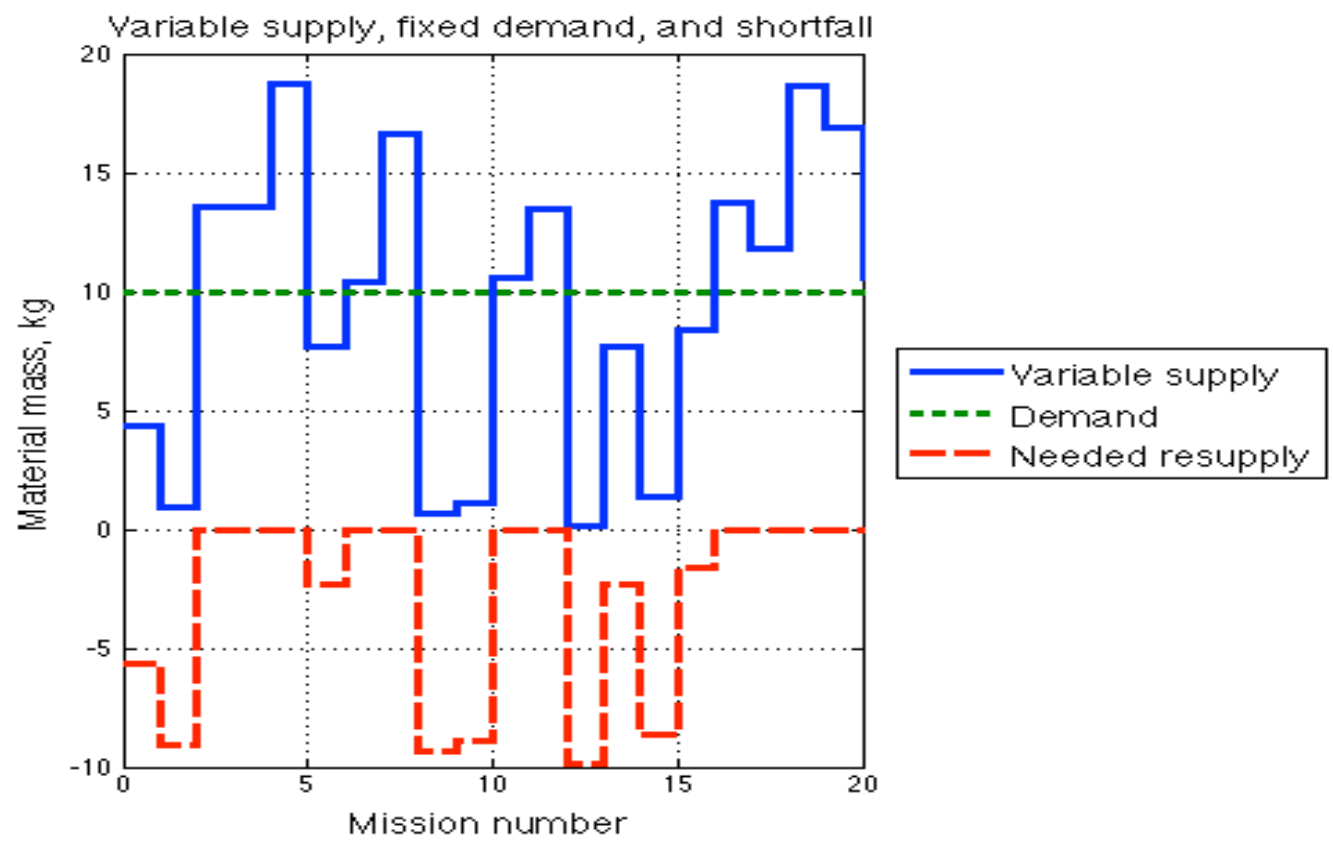

Figure 13. Demand, variable supply, and needed resupply for a sequence of twenty missions.

When the variable supply is less than the demand, as for the first two missions, the additional needed material must be resupplied from Earth. When the supply exceeds the demand, as for the following three missions, the 
demand is met but the excess supply is wasted. Even though the average of the variable supply exactly equals the demand, some of the supply is wasted and this waste must be made up by resupply. For this example, on average, only 75 percent of the supply is used, so the supply usage efficiency is 75 percent. The amount of the demand met by the variable supply is also 75 percent, and resupply is needed to meet the other 25 percent of the demand.

\section{Analysis of material supply variations}

The supply use, usage efficiency, demand coverage, and needed additional resupply for this and similar examples are computed in Table 5.

The first example is for Dfix $=10$, as in Fig. 13. The supply, S, always varies between 0 and $\operatorname{Smax}=20$. The

Table 5. Supply use, efficiency, demand coverage, and additional resupply.

\begin{tabular}{|c|c|c|c|c|}
\hline & \multicolumn{3}{|c|}{ Demand, $\mathrm{D}=\mathrm{Dfix}$} \\
\hline & & 10 & 5 & 15 \\
\hline Maximum supply & Smax & 20 & 20 & 20 \\
\hline Case 1. S > Dfix & & $10<\mathrm{S}<20$ & $5<S<20$ & $15<\mathrm{S}<20$ \\
\hline Average $\mathrm{S}$ & Savg $=($ Dfix + Smax $) / 2$ & 15 & 12.5 & 17.5 \\
\hline Average $S$ used & Dfix & 10 & 5 & 15 \\
\hline Probability S > Dfix & $($ Smax - Dfix $) / S \max$ & 0.5 & 0.75 & 0.25 \\
\hline Case 2. S $<$ Dfix & & $0<\mathrm{S}<10$ & $0<\mathrm{S}<5$ & $0<\mathrm{S}<15$ \\
\hline Average $\mathrm{S}$ & Dfix/2 & 5 & 2.5 & 7.5 \\
\hline Average S used & Dfix/2 & 5 & 2.5 & 7.5 \\
\hline Probability $\mathrm{S}<$ Dfix & Dfix/Smax & 0.5 & 0.25 & 0.75 \\
\hline Overall & & & & \\
\hline Average $\mathrm{S}$ & $\operatorname{Smax} / 2$ & 10 & 10 & 10 \\
\hline Average $\mathrm{S}$ used & $\begin{array}{c}\text { Dfix }(\operatorname{Smax}-\mathrm{Dfix}) / \mathrm{Smax})+ \\
(\mathrm{Dfix} / 2) \mathrm{Dfix} / \mathrm{Smax}\end{array}$ & 7.5 & 4.375 & 9.375 \\
\hline Efficiency of use of $\mathrm{S}$ & Average S used/ Average S & $7.5 / 10=0.75$ & $4.375 / 10=0.44$ & $\begin{array}{c}9.375 / 10= \\
0.9375\end{array}$ \\
\hline $\begin{array}{c}\text { Coverage of demand } \\
\text { Dfix }\end{array}$ & Avcragc S uscd /Dfix & $7.5 / 10=0.75$ & $4.375 / 5=0.875$ & $\begin{array}{c}9.375 / 15= \\
0.625\end{array}$ \\
\hline Average resupply & Dfix - Average S used & $10-7.5=2.5$ & $5-4.375=0.625$ & $\begin{array}{c}15-9.375= \\
5.625\end{array}$ \\
\hline $\begin{array}{l}\text { Resupply for } 20 \\
\text { missions }\end{array}$ & & 50 & 12.5 & 112.5 \\
\hline
\end{tabular}

analysis considers two cases. Case 1. $\mathrm{S}>\mathrm{Dfix}=10$, and Case 2. $\mathrm{S}<\mathrm{Dfix}=10$. For Case 1. $\mathrm{S}>$ Dfix, the average $\mathrm{S}$ is the average of Dfix and Smax, 15, and the amount Dfix $=10$ is always used. For Case 2. S $<$ Dfix $=10$, the average $S$ is Dfix $/ 2=5$ and this is the average amount of $S$ used. Since Dfix $=10=\operatorname{Smax} / 2=20 / 2$, Case 1 and Case 2 both have probability of 0.5 , and the overall average $S$ used is the average of 10 and 5 , or 7.5 . The efficiency of the use of the supply $\mathrm{S}$ is the average used divided by the average available, 0.75 . The coverage of the constant demand Dfix is the amount used divided by the amount demanded, accidentally also 0.75 . the average resupply is the difference between the demand and the supply used, 2.5, and the resupply for 20 missions is 20 times this. The probability of resupply on a mission is the probability that $\mathrm{S}<$ Dfix, which is the probability of Case 2, Dfix/Smax.

Similar examples are shown for Dfix $=5$, much less than the average supply, and for Dfix $=15$, much more than the average supply. For Dfix small, most of the supply is wasted, but most of the demand is covered and resupply from Earth is small. For Dfix large, most of the supply is used, but much of the demand is not covered and resupply from Earth is large. The total increase in resupply is much less than the total increase in demand, since more of the variable supply is utilized to meet higher demands. This simple analysis is made possible by the assumption of a uniform distribution for the variable supply.

\section{Buffering the supply variations}

Buffering is a good solution to dynamic flow variations. The likelihood of a lack of water and the need to provide more water from Earth can be reduced by providing a water storage buffer. If the average supply exceeds 
the average demand, the amount of stored water will increase. If a significantly large initial store of water is provided, the likelihood of a shortfall can be further reduced. Additional water can be supplied if random fluctuations draw the stored supply too low.

The first numerical example in Table 4, where average of the variable supply was set equal to the demand, makes the advantage of a buffer very obvious. In that case 25 percent of the supply was wasted, and 75 percent of the demand was provided by the variable supply. The missing 25 percent had to be provided by resupply from Earth. If a large buffer is provided, the excess supply on one mission can be stored for a subsequent mission. No supply is wasted and resupply is needed after a sequence of missions having low supply.

The other examples in Table 4, where the fixed demand is lower or higher than the average supply, can also benefit from the use of a buffer. Even when the average supply is twice the fixed demand, the current supply is less than the fixed demand 25 percent of the time, and 12.5 percent the demand must be met by resupply. And even when the average supply is only two-thirds of the fixed demand, the current supply is higher than the fixed demand 25 percent of the time, and, 6.25 percent of the supply is in excess of the current demand and is wasted.

A dynamic simulation is used to investigate the behavior of he system when a buffer is added. As first numerical example in Table 4, the fixed amount demanded, Dfix, is $10 \mathrm{~kg}$, and the variable supply, S, is uniformly distributed between 0 and Smax $=20 \mathrm{~kg}$. The variable supply is buffered in a tank of $50 \mathrm{~kg}$ capacity. A dynamic simulation of the tank output, tank level, and needed additional resupply for a sequence of twenty missions is shown in Fig. 14.

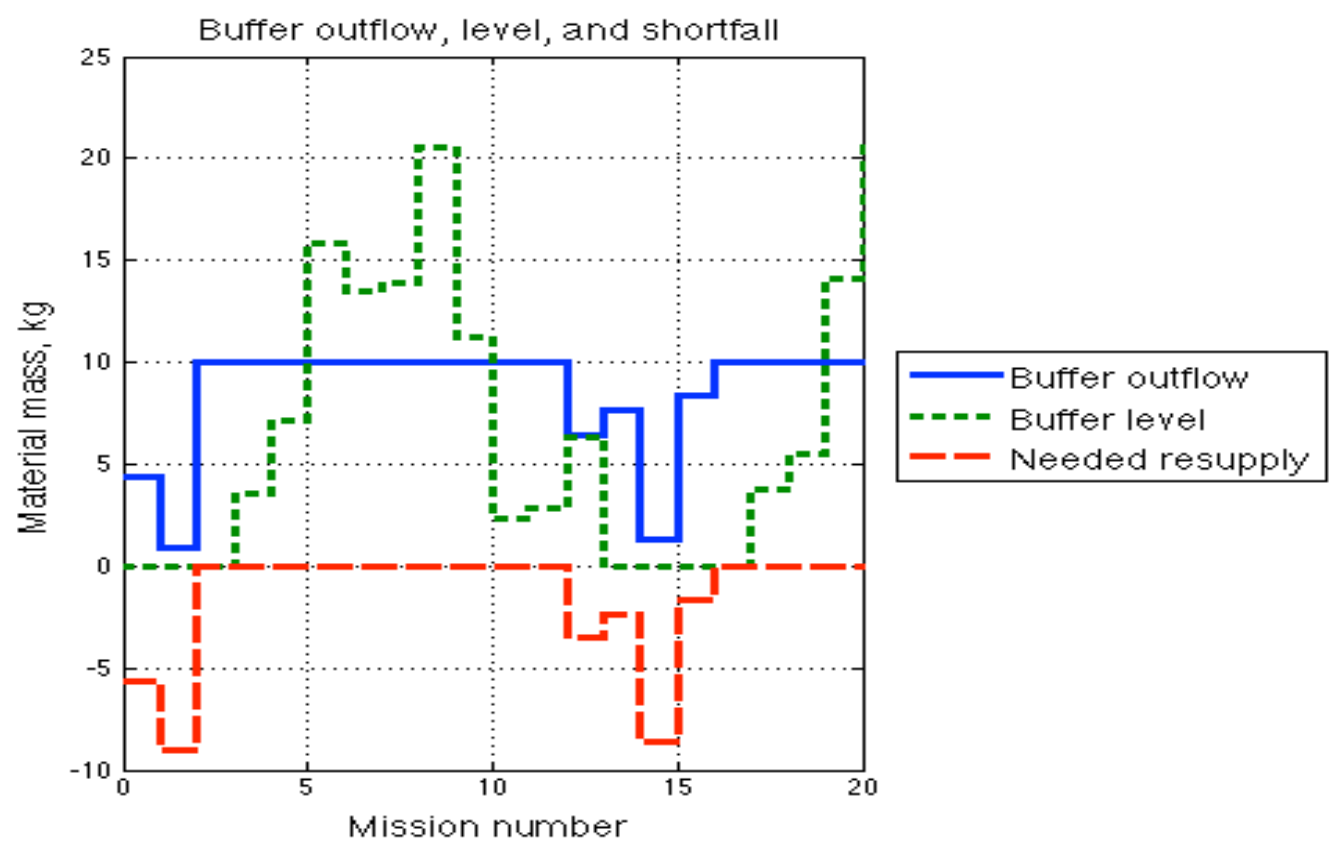

Figure 14. Buffer tank outflow, level, and needed resupply for a sequence of twenty missions.

The variable supply and fixed demand are the same as in Fig. 13. The buffer outflow includes the current supply if it is needed to meet current demand. The variable supply is less than the demand for the first two missions and additional material must be resupplied from Earth. For the following missions, supply exceeds demand and the buffer tank fills. Low variable supply on missions 8, 9, 12, and 14, shown in Fig. 13, draw the buffer level down to zero. The buffered supply and the current supply cannot meet demand, and resupply is needed on missions 12,13 , 14 , and 15. For this random sequence of supply amounts, 85 percent of the fixed demand is provided by the variable supply and 15 percent by resupply. 89 percent of the supply is used. For a large buffer and a long sequence of missions, the demand provided and supply used would approach 100 percent. With out a buffer, these numbers are 75 percent.

\section{A. Initial material stocks}

Providing an initial stock of $15 \mathrm{~kg}$ would replace the initial resupply. but more resupply would be needed for missions $12,13,14$, and 15 . Initially partly filling the buffer and maintaining it partly full would reduce the urgency of resupply but would not reduce total resupply from Earth. 


\section{B. Variable demand as well as supply}

The demand for water and oxygen may also vary, perhaps due to additional EVA or adverse EVA conditions, or because of the storage or processor failures considered above. The analysis does not change significantly if both demand and supply vary. The current mission excess or shortfall is equal to the difference between the current supply and demand. The excess can be stored and the shortfall must be made up from storage or by resupply.

However, additional sources of variation increase the possible range of variation. We assumed a uniform distribution of supply minus demand, from minus the demand to plus the demand. [ - Dfix $=-10<$ (S --Dfix) $<$ Dfix $=10]$ The range is limited and all values are equally likely. If the supply and demand were composed of many variables, the excess or shortage would have a normal or Gaussian distribution, with a value typically near the average but extreme values possible. Buffering is even more useful when here are many unpredictable variations is material supply and demand.

\section{Benefit and cost of a supply buffer}

With the buffer and example random supply, 15 percent of the demand is met by resupply, and the total resupply for the 20 missions is about $0.15 * 20 * 10=30 \mathrm{~kg}$, the demand of three missions. Without the buffer, on average 25 percent of the demand is met by resupply, and the total resupply for the 20 missions averages $0.25 * 20 * 10=50$ $\mathrm{kg}$, the buffer saves about 10 percent of the total resupply, or $20 \mathrm{~kg}$. The mass of a tank can be approximately estimated as 10 percent of its mass capacity. A storage capacity of $25 \mathrm{~kg}$ is sufficient, and would have mass of 2.5 $\mathrm{kg}$, so providing the buffer saves mass overall.

In general, providing a buffer can prevent losing any of a variable supply that is likely to be needed, at a relatively small cost. If the supply exceeds the demand on average, providing a buffer can avoid the need for resupply from Earth, but even a large buffer may become filled and some supply be lost. If the supply is on average less than the demand, a small buffer can preserve any excess supply until it is needed.

\section{Conclusion}

After a depressurization and loss of atmosphere, the most time urgent failure response is the loss of carbon dioxide removal capability. This could occur due to a carbon dioxide remover failure or to a power failure. Replacing the atmosphere to reduce the carbon dioxide level can provide only temporary relief.

Failures affecting the water system are easier to cope with if there is ample water. The case of ample water occurs when the EVA cooling water requirement is low, $2 \mathrm{~kg} / \mathrm{CM}-\mathrm{EVA}$, and fully hydrated food is supplied. Excess water is produced and a large amount can be stored over time. Scarce water occurs when the EVA cooling water requirement is high, $5 \mathrm{~kg} / \mathrm{CM}-\mathrm{EVA}$, even though hydrated food is supplied. Water is also in short supply when the EVA cooling water requirement is zero and only dehydrated food is provided. This last case has the minimum resupply cost. Its resupply could be further reduced by recovering water from brine, or by capturing EVA carbon dioxide and recycling it.

For coping with uncertainties and failures, it seems best to run a slight water surplus and to build up a large store of clean water. The general categories of resupply delays and material storage failures require increased reserve storage and isolated, divided storage. Lost recycled materials, such as water and oxygen, can be replaced over time, as long as there is an appropriate material inflow, such as hydrated food or scavenged propellant. Buffering increases the amount of a variable resource that can be used. The resupply from Earth is reduced by the same amount that the use of the variable resource is increased.

The case of ample water, where recycling can produce more water than is needed, allows for much easier recovery from failures. Ample water allows for some use of dehydrated food. The cost of resupply and the benefits of having ample water emphasize the desirability of reducing or eliminating the use of water for EVA cooling.

\section{References}

Jones, H., "Evolution of Life Support from Apollo, Shuttle, and ISS to the Vision for the Moon and Mars," 36th ICES (International Conference on Environmental Systems), SAE Technical Paper No. 2006-01-2013, Society of Automotive Engineers, Warrendale, PA, 2006.

Jones, H., "Lunar Base Life Support Failure Analysis and Simulation," 39th ICES (International Conference on Environmental Systems), SAE Technical Paper No. 2009-01-2482, Society of Automotive Engineers, Warrendale, PA, 2009.

Jones, H., "Lunar Base Life Support Mass Flow and Recycling," 38th ICES (International Conference on Environmental Systems), SAE Technical Paper No. 2008-01-2184, Society of Automotive Engineers, Warrendale, PA, 2008.

Jones, H., "Planning Dynamic Simulation of Space Life Support," 39th ICES (International Conference on Environmental Systems), SAE Technical Paper No. 2009-01-2493, Society of Automotive Engineers, Warrendale, PA, 2009. 
Jones, H., "Spacesuit Cooling on the Moon and Mars," 39th ICES (International Conference on Environmental Systems), SAE Technical Paper No. 2009-01-2418, Society of Automotive Engineers, Warrendale, PA, 2009.

Jones, H., "The Dynamic Impact of EVA on Lunar Outpost Life Support," 38th ICES (International Conference on Environmental Systems), SAE Technical Paper No. 2008-01-2017, Society of Automotive Engineers, Warrendale, PA, 2008.

Lange, K. E., "Lunar Outpost Life Support Trade Study," ESCG-4470-08-TEAN-DOC-0221, Jacobs Technology Engineering and Science Contract Group, March 2008 (SBU restricted).

Lange, K., and Anderson, M, "Lunar Outpost Life Support Architecture Study Based on a High Mobility Exploration Scenario, 40th ICES (International Conference on Environmental Systems) 2010.

Linne, D. L., Plachta, D. W., Chato, D. J., Loyselle, P. L., Sutherlin, S. G., Notardonato, W. U., Fittje, J.E., Poast, K. I., Kashani, A., Hornsby, L. S., and Kevin P. Prokopius, K. P., "Feasibility of Scavenging Propellants from Lander Descent Stage to Supply Fuel Cells and Life Support," AIAA-2009-6511, AIAA SPACE 2009 Conference \& Exposition, 14 - 17 September 2009, Pasadena, California.

Notardonato, W. U., "Recovery of lunar surface access module residual and reserve propellants," Cryogenics 48 (2008) $210-$ 216. 